\title{
LA PRODUCCIÓN DE BANANOS ASOCIADOS CON LEGUMINOSAS Y PLANTAS FORRAJERAS EN LA REPÚBLICA DOMINICANA
}

\section{The production of bananas associated with leguminous and forage plants in the Dominican Republic}

\section{Reinaldo Soriano Soriano}

Comisión Presidencial de Apoyo al Desarrollo Barrial,

Santo Domingo, República Dominicana

Correo-e: reinaldo.soriano@desarrollobarrial.gob.do

\section{Geralda Díaz}

Área de Ciencias Básicas y Ambientales, Instituto

Tecnológico de Santo Domingo (INTEC), Santo

Domingo, República Dominicana

Correo-e: geralda.diaz@intec.edu.do
Josefina Vásquez Frías

Área de Ciencias Básicas y Ambientales, Instituto

Tecnológico de Santo Domingo (INTEC), Santo

Domingo, República Dominicana

Correo-e: josefina.vazquez@intec.edu.do

Recibido: 23/7/2019 • Aprobado: 21/8/2019

Cómo citar: Soriano Soriano, R., Díaz, G., \& Vásquez Frías, J. (2019). La producción de bananos asociados con leguminosas y plantas forrajeras en la República Dominicana. Ciencia, Ambiente y Clima, 2(2), 59-65. Doi: https://doi.org/10.22206/cac.2019. v2i2.pp59-65

Resumen

Se analiza la situación de la producción de banano orgánico en la República Dominicana y el uso de leguminosas forrajeras. Se aplicaron entrevistas y encuentras para el levantamiento de la información. Los resultados evidencian que el $66.7 \%$ de los productores de bananos usan cobertura de leguminosas. Las plantas de cobertura más utilizada son: Canavalia ensiformis, Arachis pintoi, Vigna unguiculata, $V$. pedunculares y Pueraria phaseoloides.

Palabra clave: banano; leguminosa; manejo, República Dominicana.

\begin{abstract}
The situation of organic banana production in the Dominican Republic and the use of forage legumes are analyzed. Interviews were applied and found for information gathering. The results show that $66.7 \%$ of banana producers use legume coverage. The most used cover plants are: Canavalia ensiformis, Arachis pintoi, Vigna unguiculata, V. pedunculares y Pueraria phaseoloides.
\end{abstract}

Keywords: Banana; legumes; handling; Dominican Republic. 


\section{Introducción}

\section{Características del banano}

El banano pertenece a la familia de las musáceas. Estas son originarias de Asia meridional. Existen 42 especies que se clasifican dentro de los géneros: Musa, Musella y Ensete. Las hojas de las bananas están formadas por una estructura tubular llamada vaina, un pecíolo grueso y un limbo o lámina. Un grupo de numerosas vainas se disponen concéntricamente y de forma muy apretada para formar los falsos tallos, los cuales pueden poseer hasta 40 vainas durante su vida. Los bananos tienen gran número (200-500) de raíces fibrosas que salen del rizoma. En los suelos fértiles, bien drenados y profundos las raíces del banano pueden extender 5 pies $(1.5 \mathrm{~m})$ en profundidad y hasta 16 pies $(4.9 \mathrm{~m})$ lateralmente (Crane \& Balerdi, 2015).

El banano puede cultivarse desde 0 hasta los 2000 metros de altura sobre el nivel del mar, con temperatura promedio entre $22^{\circ} \mathrm{C}$ y $29^{\circ} \mathrm{C}$. Requiere de 2000 horas luz promedio anual y una precipitación de lluvias anual promedio de $2000 \mathrm{~mm}$. Los suelos más aptos para su siembra y explotación son los de reacción neutra ( $\mathrm{pH} 6.5-7)$, aunque también tolera los ligeramente ácidos y alcalinos, considerándose por lo tanto apropiado para su siembra, todos aquellos suelos que presentan un $\mathrm{pH}$ comprendido entre 5.5 y 7.2. Los suelos deben ser sueltos, ricos en materia orgánica, fértiles y con buen drenaje.

La producción de bananos orgánicos se ha convertido en uno de los mayores pilares económicos en la provincia Valverde y en otras provincias de la República Dominicana. En la actualidad, hay 1,815 productores orgánicos (Centre de coopération internationale en recherche agronomique pour le développemen [CIRAD], 2014) y unas 20,172.01 hectáreas dedicados a este cultivo. La cobertura verde previene la erosión, reduce la velocidad del agua y aporta nitrógeno al suelo. Además, esta técnica es útil como trampa para retener plagas, hongos y preservar la biodiversidad de los ecosistemas agrícolas.

\section{La producción y exportación de banano en República Dominicana}

La producción de banano en la República Dominicana se inicia en el 1896, cuando la Boston Fruit Company inició una plantación en Sabana de la Mar (Provincia Hato Mayor). Las primeras exportaciones de banano en República Dominicana fueron realizadas por la United Fruit Company en 1906 con plantaciones en Sosúa y Puerto Plata, estas fueron abandonadas por una ola de frío y enfermedades.

Sin embargo, el cultivo de bananos orgánicos en la República Dominicana se inició en 1982, cuando Mark Freedman estableció una demostrativa en Río Limpio (Provincia Elías Piña). Además, la empresa "Plantaciones Tropicales" realizó las primeras exportaciones comerciales de productos orgánicos en 1989, principalmente bananos, a Europa y los Estados Unidos. En 1994, Savid S.A. comenzó a exportar a Europa bananos orgánicos producidos en una superficie de 350 hectáreas por pequeños agricultores de la Provincia Azua.

En la República Dominicana el sector agrícola es una actividad muy importante, representa alrededor del $6.5 \%$ del Producto Interno Bruto (PIB) y genera el $21 \%$ del total de las exportaciones, e involucra la participación directa o indirecta del $31 \%$ de la población, siendo el banano un rubro de importancia.

La producción de bananos orgánicos de exportación en República Dominicana está amparada en la Ley 84-99, y las resoluciones 15-2008 y 18-2013 que funcionan como instrumentos normativos para la agricultura orgánica. La agricultura orgánica es por tanto parte integral de la Ley 1-12 que establece ticas públicas deberán incorporar criterios de sostenibilidad ambiental y adecuada gestión integral de riesgo. 
Sobre el uso de leguminosas, varios estudios se han realizado con relación a la calidad en la producción de banano, destacan entre estos: Gutiérrez, Pérez y Gómez (2002), quienes comprobaron que el uso de las leguminosas Centrosema plumieri, Teramnus Labialis y Stylosanthes guianensis provoca una reducción significativa de malezas, la reducción de plagas dañinas para el cultivo del banano y el incremento del tamaño del racimo. Sin embargo, Salazar et al., 2005, afirman que el establecimiento y el manejo de leguminosas aumenta los costos de producción.

Las leguminosas son plantas de una extensa familia que incluye una amplia variedad de especies y comprende tanto árboles, arbustos, hierbas y cultivos. Se caracterizan por sus frutos en forma de vaina, conocidos como legumbre. En la agricultura, las leguminosas se usan para mejorar la textura del suelo y agregar nitrógeno fijado por bacterias del género Rhizobium.

Respecto a estudios sobre bacterias podemos mencionar a Córdova, Rivera, Farrera, Obrador y Córdova (2009), quienes realizaron investigaciones sobre la detención de bacterias benéficas en suelos con bananos y su potencial para integrar un biofertilizante, en donde se comprobó que a mayor profundidad menor cantidad de bacterias existen. Mantilla et al., 2009, estudiaron las bacterias potencialmente fijadoras de nitrógeno y su relación con parámetros fisicoquímicos en suelos con tres coberturas vegetales diferentes. Salazar, Patińo y Bustamante (2006) llevaron a cabo estudios sobre los sustratos foliares para incremento de bacterias quitinoliticas y glucanolitica en la filosferas de banano. Posteriormente, Villarreal et al., 2013, estudiaron el índice de calidad del suelo en área cultivada de banano en Panamá, la investigación reveló la escasa actividad microbiana en el suelo, lo que influye negativamente en la producción del banano.

Desde otra perspectiva, Falco y Momo (2010) determinaron los beneficios y los efectos provocados por lombrices y nematodos en el banano. Arias, Mata,
Alvarado, Serrano y Laguna (2010) estudiaron la caracterización química y clasificación taxonómica de algunos suelos cultivados de bananos en llanuras aluviales, que demostraron la variación del $\mathrm{pH}$ y su influencia en la acidificación del suelo.

Manzo, Orozco, Martínez, Garrido y Canto (2014) describieron las enfermedades más importantes en el cultivo del banano, destacando la Sigatoka, el mal del Panamá causado por el hongo Fusarium oxysporum, la marchitez bacteriana y el virus del mosaico del banano.

Otros estudios, por ejemplo Martínez 2013, se refieren a los efectos del riego deficitario controlado en la productividad del banano, quien comprobó que el déficit hidrológico en algunas de las fases de crecimiento disminuye la producción.

Sandoval et al., 2013, en una investigación sobre los efectos de los biofertilizantes sobre la tolerancia de banano a la desinfección e inducción de organogénesis, demostraron que el uso de biofertilizantes produce mejores resultados en la supervivencia y menor contaminación del banano orgánico.

Los objetivos de la investigación fueron los siguientes: a) analizar las técnicas de manejo utilizadas para el control de la cubierta vegetal espontáneo en el cultivo del banano orgánico; b) determinar las especies de leguminosas utilizadas como forrajera, control de las malezas, reducción de la erosión y mejora de la fertilidad del suelo en el cultivo de banano orgánico.

\section{Materiales y métodos}

El estudio se realizó en la provincia Valverde, en 53 fincas productoras y en una finca experimental de la Junta Agroempresarial Dominicana (JAD). Las fincas fueron georreferenciadas. Se aplicaron entrevistas y encuestas a 53 productores, 9 técnicos de 21 asociaciones y una cooperativa de productores de banano orgánico. La información fue posteriormente analizada. 


\section{Resultados y discusión}

La certificación del banano orgánico en la provincia Valverde la realizan seis certificadoras: Kiwa, Sres, Control Unión, Qcs, Suelo Salud, Imo Caribe, y funcionan 21 asociaciones de productores de bananos orgánicos que tienen como sede la Asociación Dominicana de Productores de Banano, Inc. (ADOBANANO).

Los pequeños productores con parcelas de 1.3 hectáreas o menos no pueden tener acceso a nuevas tecnologías agrícolas como riego por goteo, fumigación, o implementación de nuevas técnicas de cultivos, por ejemplo. Muchos productores de bananos tienen gastos excesivos por el desconocimiento de nuevas tecnologías, lo cual coincide con lo expuesto por Vargas, 2013.

Los bananos requieren grandes cantidades de minerales para mantener una alta productividad en las plantaciones, destacándose la gran demanda por nitrógeno $\mathrm{y}$, especialmente, por potasio.

Las técnicas que utilizan los productores de banano orgánico en el control de las malezas son: cubierta inerte con hojas secas de bananos para prevenir el crecimiento de maleza dentro de las parcelas, el chapeo o siega para el control de la maleza, cultivos de leguminosas, plantas forrajeras y planta espontáneas.

Es evidente que la producción de bananos orgánicos ha dinamizado la economía de la provincia Valverde Mao, la cual ha pasado a ser una provincia próspera, $y$ en sus pobladores se evidencian cambios importantes, así como en la infraestructura y en los medios de transportes que circulan por sus calles.

\section{Análisis del comportamiento de la producción de bananos por provincias}

En la República Dominicana el 25 \% de los productores de bananos orgánicos tienen parcelas de $0.6 \mathrm{a}$ 1.6 hectáreas, tomando como base los productores existentes a nivel nacional. La tabla 1 indica el rango de opinión del tamaño de las parcelas que oscila entre 1 y más de mil hectáreas de uso en las provincias productoras, siendo la provincia de Azua la que cuenta con mayor porcentaje.

Tabla 1. Rango de opinión del tamaño de las parcelas productoras de banano, por provincias

\begin{tabular}{|c|c|c|c|c|c|c|c|c|c|c|c|c|c|c|}
\hline \multirow[b]{2}{*}{$\begin{array}{l}\text { OPI- } \\
\text { NIÓN }\end{array}$} & \multicolumn{2}{|c|}{$\begin{array}{c}\text { Productores según } \\
\text { tamańo de la finca. } \\
\text { Provincia de Mon- } \\
\text { tecristi }\end{array}$} & \multicolumn{2}{|c|}{$\begin{array}{l}\text { Productores según } \\
\text { tamańo de la finca } \\
\text { Provincia Valverde }\end{array}$} & \multicolumn{2}{|c|}{$\begin{array}{c}\text { Productores según } \\
\text { tamańo de la finca. } \\
\text { Provincia Azua }\end{array}$} & \multicolumn{2}{|c|}{$\begin{array}{l}\text { Productores según } \\
\text { tamańo de la finca. } \\
\text { Provincia Santiago }\end{array}$} & \multicolumn{2}{|c|}{$\begin{array}{c}\text { Productores según } \\
\text { tamańo de la finca. } \\
\text { Provincia Puerto } \\
\text { Plata }\end{array}$} & \multicolumn{2}{|c|}{$\begin{array}{l}\text { Productores según } \\
\text { tamańo de la finca. } \\
\text { Provincia Dajabón }\end{array}$} & \multicolumn{2}{|c|}{$\begin{array}{l}\text { Resultados Naciona- } \\
\text { les por Provincias }\end{array}$} \\
\hline & $\begin{array}{l}\text { FRECUEN- } \\
\text { CIA }\end{array}$ & $\%$ & $\begin{array}{c}\text { FRECUEN- } \\
\text { CIA }\end{array}$ & $\%$ & $\begin{array}{l}\text { FRECUEN- } \\
\text { CIA }\end{array}$ & $\%$ & $\begin{array}{c}\text { FRECUEN- } \\
\text { CIA }\end{array}$ & $\%$ & $\begin{array}{c}\text { FRECUEN- } \\
\text { CIA }\end{array}$ & $\%$ & $\begin{array}{l}\text { FRECUEN- } \\
\text { CIA }\end{array}$ & $\%$ & $\begin{array}{l}\text { NACIO- } \\
\text { NAL }\end{array}$ & $\%$ \\
\hline 1 A 25 & 47 & 6.9 & 25 & 4.4 & 377 & 76.5 & 1 & 1.5 & 0 & 0 & 0 & 0 & 450 & $25 \%$ \\
\hline 26 A 75 & 276 & 40.5 & 217 & 38 & 91 & 18.5 & 10 & 15.2 & & & 0 & 0 & 594 & $33 \%$ \\
\hline 76 A 150 & 155 & 22.7 & 153 & 26.8 & 10 & 2 & 26 & 39.4 & 1 & 50 & 0 & 0 & 345 & $19 \%$ \\
\hline $\begin{array}{c}151 \mathrm{~A} \\
300\end{array}$ & 136 & 19.9 & 108 & 18.9 & 4 & 0.8 & 13 & 19.7 & 0 & 0 & 0 & 0 & 261 & $14 \%$ \\
\hline $\begin{array}{c}301 \mathrm{~A} \\
500\end{array}$ & 22 & 3.2 & 34 & 6 & 6 & 1.2 & 7 & 10.6 & 0 & 0 & 0 & 0 & 69 & $4 \%$ \\
\hline $\begin{array}{c}501 \mathrm{~A} \\
1000\end{array}$ & 15 & 2.2 & 21 & 3.7 & 3 & 0.6 & 2 & 3 & 1 & 50 & 0 & 0 & 42 & $2 \%$ \\
\hline $\begin{array}{l}\text { MAS DE } \\
1000\end{array}$ & 31 & 4.5 & 13 & 2.3 & 2 & 0.4 & 7 & 10.6 & 0 & 0 & 1 & 100 & 54 & $3 \%$ \\
\hline Total & 682 & 100 & 571 & 100 & 493 & 100 & 66 & 100 & 2 & 100 & 1 & 100 & 1815 & $100 \%$ \\
\hline
\end{tabular}

Fuente: datos tomados del Censo Bananero realizado por el Proyecto BAM (Medidas de acompańamiento).

62 | Ciencia, Ambiente y Clima 2019; 2(2, julio-diciembre): 59-65 • Reseñas 
La Tabla 2 se refiere a la distribución de la superficie de la finca donde se cultivan bananos orgánicos según la actividad por provincias y a nivel nacional, se observa que las fincas donde se cultivan bananos orgánicos (Provincias Valverde, Monte Cristi, Dajabón y Azua) tienen una superficie de 20,172 hectáreas de tierra bajo cultivo de banano.

Tabla 2. Distribución de superficie por finca donde se cultivan bananos orgánicos

\begin{tabular}{|c|c|c|c|c|c|c|c|c|c|c|c|c|c|}
\hline \multirow[b]{2}{*}{ OPINIÓN } & \multicolumn{2}{|c|}{ AZUA } & \multicolumn{2}{|c|}{ DAJABÓN } & \multicolumn{2}{|c|}{ MONTE CRISTI } & \multicolumn{2}{|c|}{$\begin{array}{l}\text { PUERTO } \\
\text { PLATA }\end{array}$} & \multicolumn{2}{|c|}{ SANTIAGO } & \multicolumn{2}{|c|}{ VALVERDE } & \multirow[b]{2}{*}{$\begin{array}{l}\text { TOTAL } \\
\text { FREC }\end{array}$} \\
\hline & FREC & $\%$ & FREC & $\%$ & FREC & $\%$ & FREC & $\%$ & FREC & $\%$ & FREC & $\%$ & \\
\hline BANANO PRODUCCIÓN & 13,729 & 72.9 & 1,870 & 46.8 & 132,363 & 79.6 & 318 & 46.3 & 14,898 & 63.3 & 90,270 & 84 & 253,448 \\
\hline BANANO FOMENTO & 340 & 1.8 & 2,130 & 53.2 & 7,572 & 4.6 & 0 & 0 & 758 & 3.2 & 3,092 & 2.9 & 13,892 \\
\hline $\begin{array}{l}\text { BANANO REHABILITA- } \\
\text { CIÓN }\end{array}$ & 87 & 0.5 & 0 & 0 & 1,514 & 0.9 & 1 & 0.1 & 58 & 0.2 & 1,125 & 1 & 2,785 \\
\hline OTROS CULTIVOS & 1,324 & 7 & 0 & 0 & 3,400 & 2 & 0 & 0 & 1,124 & 4.8 & 2,093 & 1.9 & 7,941 \\
\hline INFRAESTRUCTURA & 222 & 1.2 & 0 & 0 & 1,943 & 1.2 & 6 & 0.9 & 220 & 0.9 & 1,309 & 1.2 & 3,700 \\
\hline ÁREAS SIN CULTIVOS & 2,957 & 15.7 & 0 & 0 & 14,553 & 8.8 & 359 & 52.3 & 1,182 & 5 & 7,147 & 6.7 & 26,198 \\
\hline SETO ROMPEVIENTOS & 23 & 0.1 & 0 & 0 & 712 & 0.4 & 0 & 0 & 0 & 0 & 179 & 0.2 & 914 \\
\hline ÁREA BOSCOSA & 150 & 0.8 & 0 & 0 & 4,146 & 2.5 & 3 & 0.4 & 5,301 & 22.5 & 2,257 & 2.1 & 11,857 \\
\hline Total & 18,832 & 100 & 4,000 & 100 & 166,203 & 100 & 687 & 100 & 23,541 & 100 & 107,472 & 100 & 320,735 \\
\hline
\end{tabular}

Fuente: datos tomados del censo realizado en el 2014 por el proyecto BAN (Medida de acompańamiento del banano en República Dominicana) publicado en la en su página de internet SIBA (Sistema de Información Bananera República Dominicana). Las frecuencias indican las cantidades de tareas de tierra dedicadas a las actividades descrita.

En cuanto a la utilización de los profesionales de la agronomía el $67.9 \%$ de las asociaciones tienen sus propios técnicos. En tanto que el $18.9 \%$ utiliza los de la cooperativa donde están afiliados. Además, el
$3.8 \%$ utiliza agrónomos contratados y solo el $1.9 \%$ está utilizando los técnicos del Estado y un $7.5 \%$ utiliza otros (tabla 3).

Tabla 3. Asistencia técnica de profesionales del área agronomía

\begin{tabular}{|c|c|c|c|c|}
\hline & Frecuencia & Porcentaje & Porcentaje válido & Porcentaje acumulado \\
\hline Agrónomo contratado & 2 & 3.8 & 3.8 & 3.8 \\
\hline Técnico cooperativo & 10 & 18.9 & 18.9 & 22.6 \\
\hline Técnico asociación & 36 & 67.9 & 67.9 & 90.6 \\
\hline Técnico gobierno & 1 & 1.9 & 1.9 & 92.5 \\
\hline Otros & 4 & 7.5 & 7.5 & 100.0 \\
\hline Total & 53 & 100.0 & 100.0 & \\
\hline
\end{tabular}

Fuente: elaboración propia. 
La variedad más utilizada de bananos es la Cavendish con un $88.9 \%$ y un $11.1 \%$ corresponde a Cavendish gran enana.

Un $66.7 \%$ usan cobertura de leguminosas. Sin embargo, la mayoría de los productores de bananos orgánicos no utilizan coberturas vivas para el control de las malezas. Las principales especies de leguminosas cultivadas en las plantaciones de banano orgánico en la Provincia Valverde coinciden con las presentadas por los estudios realizados por Gutiérrez et al., 2002, que indican que las coberturas vivas con leguminosas Centrosema plumieri, Teramnus labialis y Stylosanthes guianensis, provoca una reducción significativa de malezas, la reducción de plagas dañinas para el cultivo del banano y el incremento del tamaño del racimo.

Hemos observado que la aplicación de cultivos con coberturas son una técnica agrícola eficiente en control de maleza por lo que previenen el uso de agro tóxicos, además conservan la humedad del suelo y son útiles como barrera trampa para atrapar insectos que provocan daños a los cultivos.

En la producción de bananos orgánicos, el $59.7 \%$ de los productores utiliza como fertilizante principal el potasio; $24.7 \%$ utiliza compost; $9.5 \%$ utiliza nitrógeno y un $6.1 \%$ utiliza otros abonos (aminoácidos, fósforo, magnesio y zinc).

\section{Limitaciones en la producción de banano}

El tipo de riego utilizado mayoritariamente en la producción de banano es por gravedad, $96.4 \%$ de los productores, el resto, (3.6\%) utiliza gravedad por bombeo. Los terrenos donde se cultiva banano orgánico se caracterizan por ser planos (96\%), lo que facilita su inundación por el sistema de riego por gravedad. A esto se suma la alta densidad de plantación que impide la germinación de las especies sembradas. Una de las técnicas culturales que dificultan el establecimiento de las plantas de cobertura es el deshijado de las hojas del banano, que es dejado sobre el suelo para su descomposición progresiva. Aunque esta técnica favorece la fertilidad del suelo al contribuir al cierre del ciclo de nutrientes del cultivo, dificulta el establecimiento de las plantas de cobertura, que no germinan bajo las hojas del banano.

\section{Conclusiones y recomendaciones}

Un $31.5 \%$ de los productores de bananos orgánicos en República Dominicana están ubicado en la provincia Valverde, los cuales cultivan el $33.5 \%$ de la superficie dedicada a esta producción.

El monocultivo de banano estimula la proliferación de plagas como la Sigatoka negra (Mycosphaerella fijiensis), el trips y el picudo negro (Cosmopolites sordidus).

Se identificaron tres especies aplicadas en el control de las malezas entre los productores (Maní forrajero, la Canavalia, y el Frijolito).

El árbol más indicado para ser utilizada como "cortina rompe viento" es el de uva de playa (Coccoloba uvifera).

Los fenómenos naturales tropicales como huracanes, lluvias torrenciales e inundaciones provocan afectación, siendo las inundaciones las causantes de más daños en los sistemas de producción de los bananos en las provincias productoras, específicamente caída y pudrición radicular.

Es necesario que las asociaciones productoras de banano orgánico promuevan charlas motivacionales, sobre sus experiencias en cultivo de las especies de leguminosas que ellos más utilizan, partiendo de los beneficios que les ofrece como cultivo de cobertura.

Se le recomienda usar las siguientes especies: Arachis pintoi (Maní forrajero), Canavalia ensiformis 
(Canavalia), Centrosema pubescens, C. macrocarpum, Crotalaria sp., Desmodium ovalifolium, Eleusine coracana, Galactia striata, Neonotonia wightii, Pueraria phaseoloide, Stizolobium aterreum, S. deeringianum, $S$. niveum, Stylosanthes guianensis, y Vigna unguiculata, para evitar la erosión del terreno, aporte de nitrógeno y materia orgánica.

\section{Referencias}

Arias, F., Mata, R., Alvarado, A., Serrano E., \& Laguna, J. (2010). Caracterización química y clasificación taxonómica de algunos suelos cultivados de bananos en llanuras aluviales del Caribe de Costa Rica. Agronomía Costarricense, 34(2), 177-195.

Arias P., Dankers, C., Liu P., \& Pilkauskas P. (2004). La economía mundial del banano 1985-2002. Roma, Italia: Publicaciones FAO.

Centre de coopération internationale en recherche agronomique pour le développemen [CIRAD]. (2014). Agricultural Research for Development. Annual Report: Results and prospects. 68 p.

Córdova, Y., Rivera, R., Farrera, J., Obrador, J., \& Córdova, V. (2009.) Detección de bacterias benéficas en suelos con bananos (Musa AAA Simmonds) cultivar "Gran eneno" y su potencial para integrar un biofertilizante. Universidad y Ciencia. Trópico Húmedo, 25(3), 253-265.

Crane, J. H., \& Balerdi, C. F. (2015). Banana Growing in the Florida Home Landscape. Florida, Estados Unidos: IFS Extension. University of Florida. $10 \mathrm{p}$.

Falco, L. \& Momo, F. (2010) Selección de hábitat: Efecto de la cobertura y tipo de suelo en lombrices de tierra. Acta Zoológica Mexicana, 2, 179-187.

Gutierrez, I. R., G. Pérez, G., Benegra, R. \& Gómez, L. (2002). La cobertura viva de leguminosas en el plátano (Musa sp.) FHIA 03. Cultivos Tropicales, 23(2), 11-17.

Manzo-Sánchez, G., Orozco-Santos, M., Martínez-Bolaños, L., Garrido-Ramírez, E. \& Canto-Canche,
B. (2014) Enfermedades de importancia cuarentenaria y económica del cultivo de banano (Musa sp.) en México. Revista Mexicana de Fitopatología 32(2), 88-107.

Mantilla, A., Cardona, G., Peña, C., Murcia, U., Rodríguez, M. \& Zambrano, M. (2009). Distribución de bacterias potencialmente fijadoras de nitrógeno y su relación con parámetros fisicoquímicos en suelos con tres coberturas vegetales en el sur de la Amazonia colombiana. Revista de Biología Tropical, 57(4), 915 - 927.

Martínez Varona, R. (2013). Efecto del riego deficitario controlado en la productividad del banano. Revista Ciencias Técnicas Agropecuarias 22(2). Recuperado de http://scielo. sld.cu/scielo.php?script=sci_arttext\&pid= S2071-00542013000200009.

Salazar, A., Pantoja, A. \& Ortiz, J. (2005). Mucuna deeringiana (Bort) Merr. y el picudo del cormo, Cosmopolites sordidus Germar (Coleoptera: Curculionidae) en Plátano. The Journal of Agriculture of University of Puerto Rico, 89(3-4), 201-210.

Salazar, L., Patińo, L. \& Bustamante, E. (2006). Los Sustratos Foliares para Incremento de Bacterias Quitinolíticas y Glucanolíticas en la Filosfera de Banano. Revista Facultad Nacional de Agronomía. Medellin, 59(2), 3449-3465.

Sandoval, G., L. Iracheta, C. Cruz, M. Adriano, P. López, \& Sandoval, A. (2013). Efectos de biofertilizantes sobre la tolerancia de banano a la desinfección e inducción de organogénesis. Revista Chapingo. Serie Horticultura, 19(2), 183-190.

Vargas, A. (2013). Evaluación de prácticas asociadas con la remoción de flores, frutos

laterales o centrales y/o del primer mano basal en el racimo de banano. Agronomía Costarricense 37(1), 71-90.

Villarreal-Núnez J., Pla-Sentis, I., Agudo-Martínez, L., Villaláz-Perez, J., Rosales, F. \& Pocasangre, L. (2013). Índice de calidad del suelo en área cultivad de banano en Panamá. Agronomía Mesoamericana, 24(2), 301-315. 